\title{
Metformin-associated Chemopreventive Effects on Recurrence After Hepatic Resection of Hepatocellular Carcinoma: From In Vitro to a Clinical Study
}

\author{
WOO-HYOUNG KANG ${ }^{1 *}$, EUNYOUNG TAK ${ }^{2 *}$, SHIN HWANG ${ }^{1}$, GI-WON SONG ${ }^{1}$, EUNKYOUNG JWA ${ }^{1}$, \\ YOUNG-JOO LEE ${ }^{1}$, KI-HUN KIM ${ }^{1}$, CHUL-SOO AHN ${ }^{1}$, DEOK-BOG MOON ${ }^{1}$, TAE-YONG HA ${ }^{1}$, \\ DONG-HWAN JUNG ${ }^{1}$, GIL-CHUN PARK ${ }^{1}$, KYOUNG-JIN LEE ${ }^{2}$, NAYOUNG KIM ${ }^{2}$ and SUNG-GYU LEE ${ }^{1}$ \\ ${ }^{1}$ Department of Surgery and ${ }^{2}$ Asan Institute of Life Sciences, Asan Medical Center, \\ University of Ulsan College of Medicine, Seoul, Republic of Korea
}

\begin{abstract}
Background/Aim: We investigated metformininduced cytotoxic effects in vitro and assessed the chemopreventive effects of metformin in patients undergoing hepatic resection (HR) for hepatocellular carcinoma (HCC). Materials and Methods: This study consisted of laboratory and clinical studies. Results: In vitro study using HCC cell lines revealed noticeable cytotoxic effects of metformin, that were largely weaker than those of sorafenib. In the clinical study, no statistical differences were found in tumor recurrence or overall survival between metformin and control groups. In contrast, there was a non-significant difference in tumor recurrence between metformin and propensity score-matched control groups, but there was a significant difference in overall patient survival. Metformin administration was an independent risk factor for patient survival. Conclusion: In conclusion, our in vitro laboratory study demonstrated the presence of cytotoxic effects of metformin. Metformin administration was associated with reduced tumor recurrence and helped induce significant improvements in overall patient survival in patients who underwent $\mathrm{HR}$ for $\mathrm{HCC}$.
\end{abstract}

Hepatocellular carcinoma (HCC) is one of the most common malignancies and a leading cause of cancer-related death (1, 2). Hepatic resection (HR) is considered a first-line treatment

*These Authors contributed equally as first co-authors.

Correspondence to: Dr. Shin Hwang, Department of Surgery, Asan Medical Center, University of Ulsan College of Medicine 88 Olympic-ro 43-gil, Songpa-gu, Seoul 05505, Republic of Korea. Tel: +82 230103930, Fax: +82 230106701, e-mail: shwang@amc.seoul.kr

Key Words: Hepatocellular carcinoma, diabetic mellitus, hepatic resection, metformin, recurrence. in patients with preserved hepatic function, but the incidence of tumor recurrence is high after curative HR $(3,4)$. Several studies have reported the antitumor effects of new agents as postoperative adjuvant therapy following HR, but the clinical impacts of these studies have been limited (5-8). To date, no well-established strategy for lowering the risk for HCC recurrence after $\mathrm{HR}$ is accepted.

Metformin is a biguanide agent used to treat type 2 diabetes mellitus (DM). It regulates the blood sugar by improving insulin sensitivity and reducing hepatic glucose output through inhibition of gluconeogenesis and glycogenolysis. Recently, metformin has proven capable of inhibiting cancer cell growth by inducing cell cycle arrest and enhancing apoptosis (9-12). A considerable number of studies found that metformin plays a chemopreventive role in other cancers and is associated with reduced risk for HCC (13-15). Although a few high-volume populationbased retrospective studies have suggested the possibility of chemopreventive activity in metformin, the effects of metformin on post-resection HCC recurrence remain unclear.

Therefore, in our current study we investigated whether metformin has cytotoxic effects on liver tumor cell lines in vitro and further assessed the chemopreventive effects of metformin on HCC recurrence following HR through a propensity score-matched clinical study.

\section{Patients and Methods}

Study design. This study consisted of two independent parts: a laboratory research and a clinical study to assess the antitumor effects of metformin. The laboratory research assessed whether exposure to metformin has any cytotoxic effect on liver tumor cell lines. In the clinical study, the rate of tumor recurrence and overall patient survival after HR of HCC were investigated to assess whether long-term exposure to metformin has any chemopreventive effects. These study protocols were approved by the Ethics 
Committee for Animal Study at the Asan Institute of Life Sciences and the institutional review board of the Asan Medical Center (AMC-IRB 2017-0576).

Liver tumor cell lines. We used three liver tumor cell lines, one established cell line and two patient-derived xenograft (PDX) tumor cell lines. First, because a majority of HCC patients in Korea have hepatitis B virus (HBV) infection, we chose the HepG2.2.15 cell line (Korean Advanced Institute of Science and Technology), which is derived from the human hepatoblastoma cell line HepG2 with HBV transfection. This liver tumor cell line was cultured in Dulbecco's modified Eagle's medium supplemented with $10 \%$ fetal bovine serum, both purchased from Gibco-BRL (Grand Island, NY, USA). Second, we established two PDX tumor cell lines. Small pieces of human HCC tissue were obtained during hepatic resection for $\mathrm{HCC}$ in $\mathrm{HBV}$-associated patients who had not undergone any preoperative HCC treatment $(n=2)$. A small tumor fragment of $0.3 \mathrm{~g}$ was implanted subcutaneously in the bilateral hind flanks in a non-obese diabetic/severe combined immunodeficiency (NODSCID) mouse. After tumor growth for 3 months was confirmed, the tumor was harvested and implanted into a NOD-SCID mouse. After stable tumor growth was confirmed, the established first-generation xenograft tumor was serially implanted in an SCID mouse to expand the xenograft tumors, which were also implanted subcutaneously into the nude mouse for further tumor expansion. These tumors were harvested to establish new PDX tumor cell lines.

In vitro study using liver tumor cell lines. The cytotoxic effects of metformin were evaluated using the abovementioned three liver tumor cell lines. The in vitro drug concentration was determined to be $5-10 \mathrm{mmol} / \mathrm{ml}$ for metformin after repeated titration from 5 to $40 \mathrm{mmol} / \mathrm{ml}$, with consideration of the therapeutic ranges in patients with type 2 diabetes (16). To quantitatively assess metforminassociated cytotoxicity, we used a $10 \mu \mathrm{mol} / \mathrm{ml}$ concentration of sorafenib as a reference control (17).

To assess cell viability, a 3-(4,5-Dimethylthiazol-2-yl)-2,5diphenyltetrazolium bromide (MTT) assay was performed to quantify cell viability using 12 -well plates. Optical density was assessed at $550 \mathrm{~nm}$ using a microplate reader (Bio-Rad, Hercules, CA, USA). Cell survival was expressed as the percentage of the absorbance of drug-treated cells relative to that of untreated cells. MTT was purchased from Duchefa (Haarlem, the Netherlands). The cells were also observed under fluorescence microscopy after 4',6diamidino-2-phenylindole (DAPI)-Hoechst staining (Sigma-Aldrich; Poole, Dorset, UK).

Propensity score-matched clinical study using a single-institution cohort. The HCC database at our institution was searched to identify patients who had undergone primary HR for HCC during the 9 years from January 2006 to December 2013. To objectively compare the study groups, patients were narrowly selected according to the following selection criteria: solitary HCC of $2-5 \mathrm{~cm}$ in diameter, curative surgery with anatomical HR, no macroscopic vascular invasion, no extrahepatic metastasis including lymph node metastasis, no preoperative HCC treatment, and Child-Pugh class A. Through this screening process, 939 patients were selected.

These patients were classified according to postoperative administration of metformin for control of DM. Metformin use was defined as a prescription of metformin of more than 12 months within the initial 2 years following HR for HCC. To assess long- term outcomes related to the defined metformin use, 54 patients who survived for less than 2 years after HR were excluded, leaving 885 patients who survived $\geq 2$ years as the complete study cohort. Finally, 45 patients were grouped into the metformin group, and the 840 remaining patients were the control group. The sample number for the propensity score-matching (PSM) control group was estimated using a type I error $(\alpha)$ of 0.1 and a type II error $(\beta)$ of 0.20 , in addition to a $10 \%$ survival difference; as a result, the sample number of the PSM control group became 225. To overcome possible selection bias, PSM was conducted between the metformin study group and the control group, using multiple logistic regression and a 1:5 matching requirement via the nearestneighbor matching method (18). We matched baseline characteristics (age, sex), background liver disease (viral hepatitis versus others), preoperative level of tumor markers ( $\alpha$-fetoprotein [AFP] and des- $\gamma$-carboxy prothrombin [DCP; or proteins induced by vitamin $\mathrm{K}$ antagonist or absence-II]), tumor characteristics (size and presence of microvascular invasion), and AFP-DCP-tumor volume (ADV) score $(19,20)$.

Medical records were retrospectively reviewed after approval by the institutional review board of our institution. The preoperative evaluation, follow-up, and treatment for HCC recurrence have been described previously $(4,21)$. Patients were followed up until June 2017 using medical record reviews and with the assistance of the National Health Insurance Service, resulting in a patient follow-up period of $\geq 30$ months or until death. All patients were followed to identify their survival status.

Statistical analysis. Numerical data are presented as means with standard deviations or as medians with ranges. Continuous variables were compared using the Student's $t$-test, and incidence variables were compared using the chi-square test. Survival curves were estimated using the Kaplan-Meier method and compared with the log-rank test. Cox proportional hazards regression was used for multivariate survival analyses. $p$-Values $<0.05$ were considered statistically significant. Statistical analyses were performed using SPSS version 22 (IBM, NY).

\section{Results}

In vitro cytotoxicity in cell lines. To assess cell survival, we performed an MTT assay, which showed a concentrationdependent decrease in cell survival for 20-h treatment with 5 and $10 \mathrm{mmol} / \mathrm{ml}$ metformin in the HepG2.2.15 cell line (Figure 1A); this response was greater than treatment with 10 and $20 \mu \mathrm{mol} / \mathrm{mL}$ sorafenib. Cell death was lower after metformin treatment than after sorafenib treatment in PDX cell lines 1 and 2 (Figure $1 \mathrm{~B}$ and $\mathrm{C}$ ). Fluorescence microscopy with DAPI-Hoechst staining indicated noticeable apoptosis after exposure to metformin in all three cell lines; the results were similar after sorafenib exposure (Figure 2).

Patient demographics and post-resection outcomes according to metformin administration. The process of patient selection is depicted in Figure 3. The clinicopathological features of patients belonging to the metformin study group $(n=45)$, the non-metformin all control group ( $\mathrm{n}=840)$, and the PSM control group $(\mathrm{n}=225)$ are given 


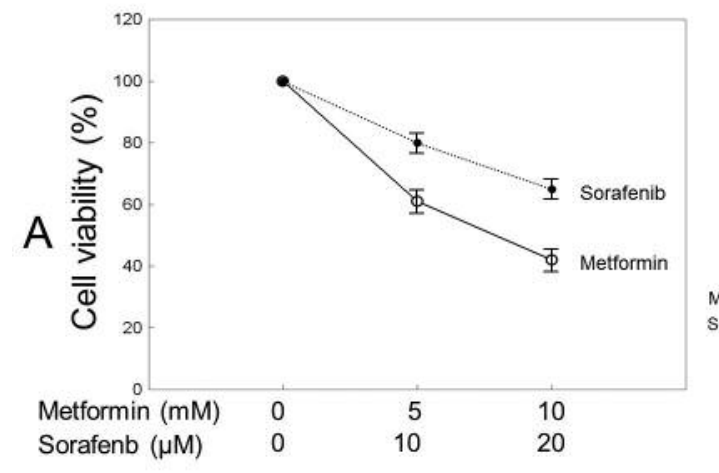

HepG2.2.15
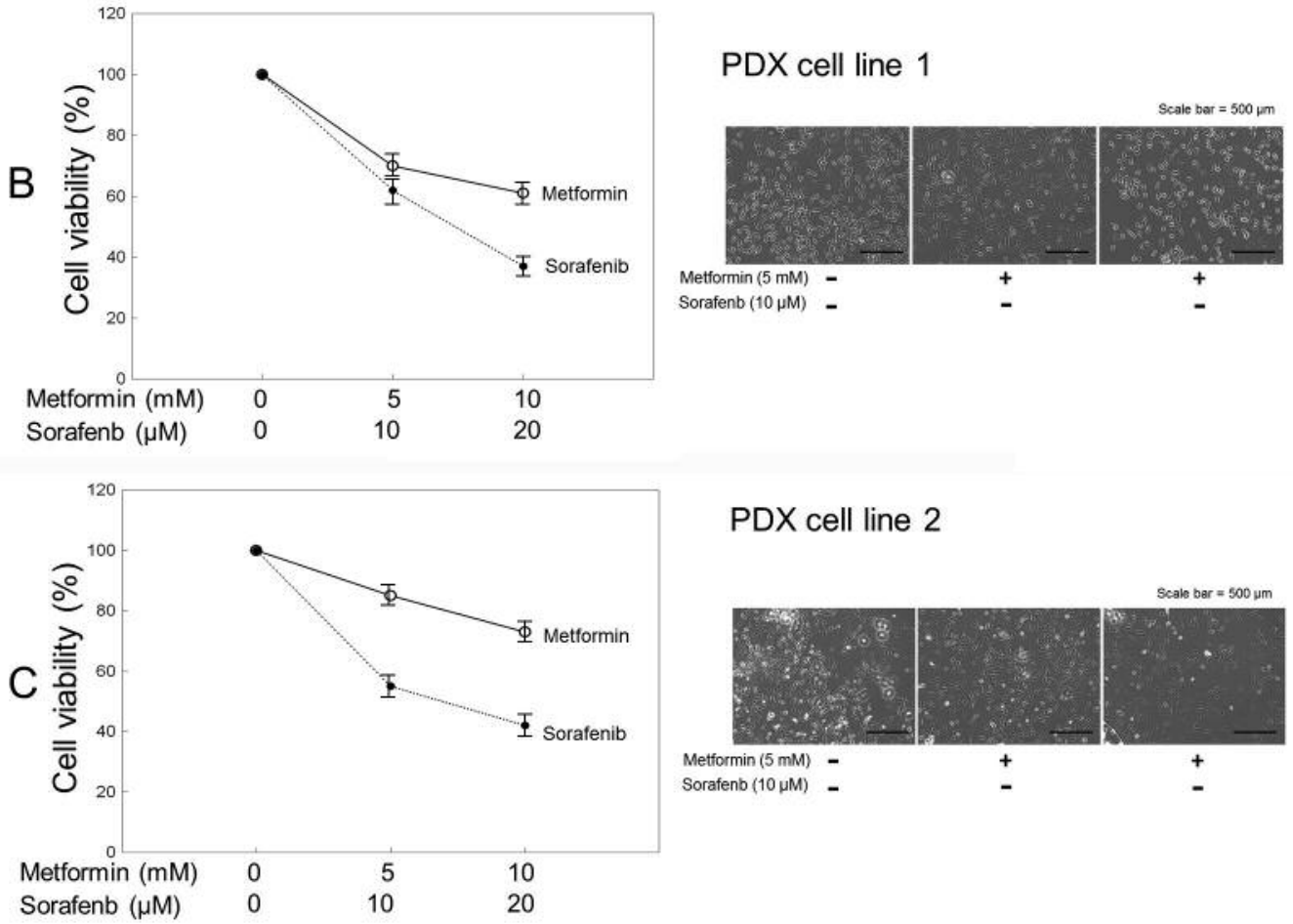

\section{PDX cell line 2}

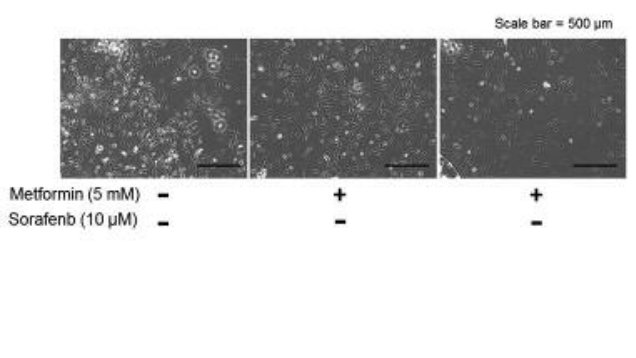

Figure 1. MTT assay for cell survival assessment using HepG2.2.15 (A) and patient-derived xenograft (PDX) tumor cell lines 1 (B) and 2 (C) with metformin and sorafenib treatment.

in Table I. The data for the metformin and PSM control groups are very similar. During follow-up, a median period of 62 months (range=24-135 months), HCC recurrence developed in 351 of 885 patients $(39.7 \%)$ and all-cause death occurred in 118 of 885 patients $(13.3 \%)$.

Tumor recurrence rates after HR according to metformin administration were compared: the 1-, 3- and 5-year rates were $11.1 \%, 32.3 \%$, and $42.4 \%$ in the metformin study group; $13.7 \%, 34.3 \%$, and $42.7 \%$ in the control group $(p=0.61)$ (Figure 4A); and $17.7 \%, 42.0 \%$, and $54.5 \%$ in the PSM control group ( $p=0.083)$, respectively (Figure 5A). For overall survival, the data were $100 \%, 97.8 \%$, and $83.2 \%$ in the metformin study group; $100 \%, 96.4 \%$, and $88.6 \%$ in the all control group ( $p=0.52$ ) (Figure 4B); and 100\%, 89.5\%, and $67.8 \%$ in the PSM control group $(p=0.028)$, at 2,3 , and 5 years, respectively (Figure $5 \mathrm{~B}$ ).

Risk factor analysis for tumor recurrence and overall survival. The results of univariate analyses for post-resection prognosis are given in Table II. Significant risk factors were tumor size $>3.1 \mathrm{~cm}$ and microvascular invasion for tumor recurrence; and tumor size $>3.1 \mathrm{~cm}$ and metformin administration for patient survival. Multivariate analyses revealed that independent risk factors were tumor size $>3.1 \mathrm{~cm}$ for tumor recurrence; and tumor size $>3.1 \mathrm{~cm}$ and metformin administration for patient survival (Table III). 


\section{HepG2.2.15}

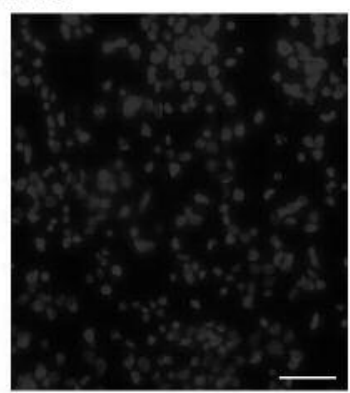

Metformin $(5 \mathrm{mM})$

Sorafenb $(10 \mu \mathrm{M})$

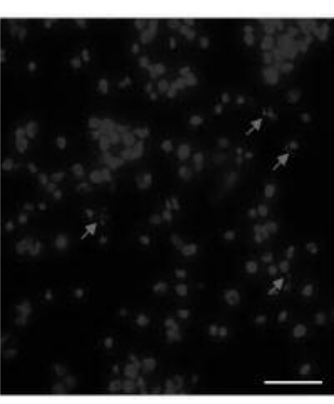

$+$

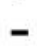

Scale bar $=50 \mu \mathrm{m}$

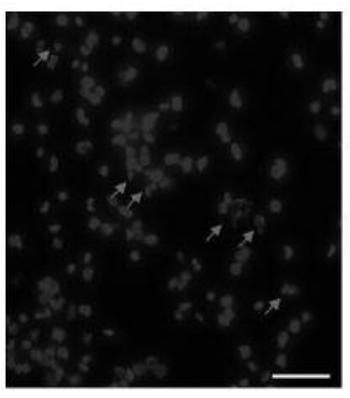

-

$+$

Figure 2. Fluorescence microscopy with DAPI-Hoechst staining in the HepG2.2.15 cell line with treatment of metformin or sorafenib. Arrows indicate apoptosis.

\section{Discussion}

For patients with $\mathrm{HCC}$ and preserved hepatic function, HR is a first-line treatment, but tumor recurrence is high even after curative $\operatorname{HR}(3,4)$. Thus, there have been many attempts to decrease the risk for tumor recurrence by postoperative adjuvant therapy such as interferon Alfa-2b, acyclic retinoid, vitamin $\mathrm{K}$, and so on (5-8), but none of these has proven effective in a prospective controlled trial setting. Vitamin $\mathrm{K}$ administration has been reported to have antitumor effects in a few patients, but meta-analyses, including a randomized controlled study, have failed to prove its preventive and therapeutic effects $(22,23)$. Researchers have also found that oral administration of vitamin $\mathrm{K} 2$ with or without sorafenib does not show adverse side-effects and that noticeable antitumor effects occur in some patients with HCC recurrence after HR or liver transplantation $(24,25)$. Therefore, there is a need to discover agents that would be usable in an adjuvant chemopreventive setting.

DM is a common chronic disease that is not life threatening in the short term and is estimated to affect $4-5 \%$ of the population worldwide. Along with the increasing prevalence of the Western lifestyle and obesity in the general population, the prevalence of DM is expected to increase rapidly in Asian countries, including Korea. DM per se is not life-threatening as a disease, but severe forms can be accompanied by serious complications that lead to deterioration of quality of life and even death. Moreover, there are accumulating data showing that patients with DM are also prone to the development of cancers, including HCC (26-31). Thus, a considerable number of patients with HCC have had DM.

A nationwide Taiwanese study found that DM has an adverse effect on patients with HCC regardless of treatment modality, but the use of metformin significantly reduces the risk for HCC

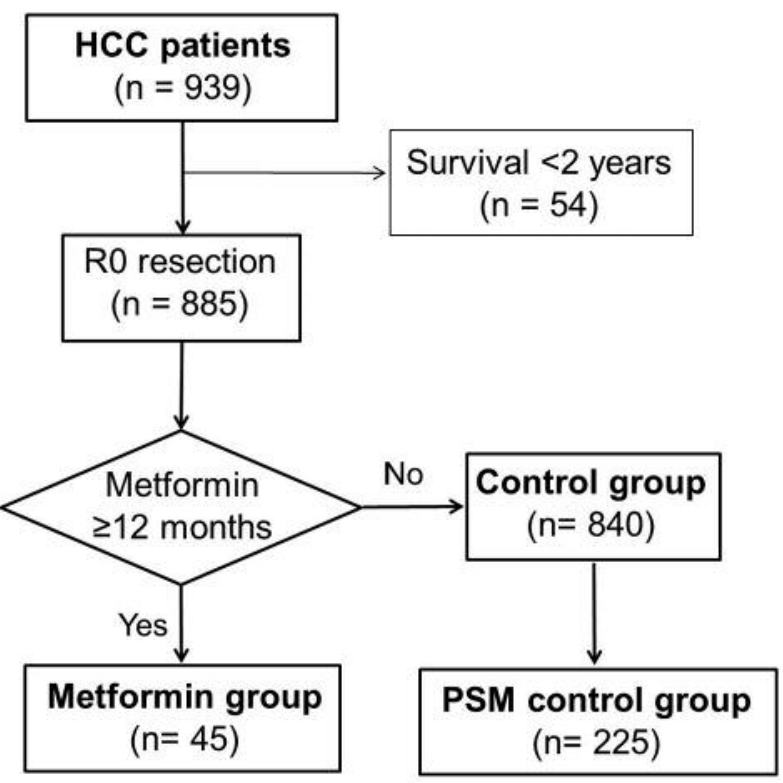

Figure 3. Selection process of the study patients for metformin, control and propensity score-matching (PSM) control groups.

recurrence and improves the overall outcome of patients after HR if patients survive the first 2 years (32). In our current study, there was a noticeable reduction in the rates of post-resection tumor recurrence in the metformin study groups compared to the PSM control group; however, this was not statistically significant, probably due to the relatively small number of cases. In contrast, there was a significant improvement in overall patient survival in the metformin group.

A few studies have investigated the association between antidiabetic drugs and the risk for developing $\mathrm{HCC}$ and have 
Table I. Comparison of clinicopathological profiles of patients in the metformin and control groups.

\begin{tabular}{|c|c|c|c|c|c|}
\hline Parameter & $\begin{array}{l}\text { Metformin group } \\
\text { (A) }\end{array}$ & $\begin{array}{l}\text { Control group } \\
\text { (B) }\end{array}$ & $\begin{array}{l}\text { PSM control } \\
\text { group }(\mathrm{C})\end{array}$ & $\begin{array}{l}p \text {-Value } \\
(\mathrm{A} v s . \mathrm{B})\end{array}$ & $\begin{array}{c}p \text {-Value } \\
\text { (A vs. C) }\end{array}$ \\
\hline Patient number & 45 & 840 & 225 & & \\
\hline Age (years) & $60.8 \pm 8.6$ & $57.4 \pm 9.5$ & $58.4 \pm 8.5$ & 0.021 & 0.11 \\
\hline Gender (Male/Female) (n) & $35 / 10$ & $671 / 169$ & $179 / 46$ & 0.73 & 0.79 \\
\hline Background liver disease (n) & & & & $0.006 *$ & $0.060^{*}$ \\
\hline HBV & 31 & 710 & 183 & & \\
\hline $\mathrm{HCV}$ & 4 & 37 & 12 & & \\
\hline ALD & 6 & 39 & 15 & & \\
\hline Others & 4 & 54 & 15 & & \\
\hline \multicolumn{6}{|l|}{ Preoperative blood laboratory profiles $($ mean $\pm S D)$} \\
\hline Albumin $(\mathrm{g} / \mathrm{dl})$ & $3.8 \pm 0.5$ & $3.8 \pm 0.4$ & $3.8 \pm 0.4$ & 0.98 & 0.97 \\
\hline $\mathrm{AST}(\mathrm{IU} / \mathrm{L})$ & $38.2 \pm 25.4$ & $38.7 \pm 38.5$ & $41.4 \pm 33.3$ & 0.93 & 0.26 \\
\hline ALT (IU/L) & $36.2 \pm 20.5$ & $39.6 \pm 45.2$ & $43.3 \pm 38.5$ & 0.62 & 0.23 \\
\hline Total bilirubin (mg/dl) & $0.8 \pm 0.4$ & $0.8 \pm 0.4$ & $0.8 \pm 0.4$ & 0.97 & 0.98 \\
\hline Platelet count $\left(10^{3} / \mu \mathrm{l}\right)$ & $163.5 \pm 46.2$ & $159.3 \pm 55.2$ & $156.5 \pm 48.3$ & 0.62 & 0.37 \\
\hline Prothrombin time (INR) & $1.02 \pm 0.07$ & $1.08 \pm 0.09$ & $1.03 \pm 0.07$ & 0.021 & 0.12 \\
\hline $\mathrm{AFP}(\mathrm{ng} / \mathrm{mL})$ at operation & & & & 0.37 & 0.55 \\
\hline Mean \pm SD & $176.1 \pm 652.9$ & $884.9 \pm 3814.2$ & $274.2 \pm 2881.2$ & & \\
\hline Median & 8.2 & 14.5 & 6.7 & & \\
\hline$\leq 7.5 />7.5 \mathrm{ng} / \mathrm{ml}(\mathrm{n})$ & $21 / 24$ & $336 / 504$ & $116 / 109$ & & \\
\hline PIVKA-II (mAU/mL) at operation & & & & 0.30 & 0.83 \\
\hline Mean \pm SD & $157.8 \pm 319.3$ & $464.8 \pm 1497.6$ & $234.4 \pm 711.3$ & & \\
\hline Median (range) & 47 & 53 & 39 & & \\
\hline$\leq 40 />40 \mathrm{mAU} / \mathrm{m}(\mathrm{n})$ & $22 / 23$ & $345 / 495$ & $114 / 111$ & & \\
\hline ICG-R15 (\%) & $13.9 \pm 8.2$ & $13.0 \pm 5.5$ & $12.8 \pm 5.7$ & & \\
\hline MELD score $($ Mean \pm SD $)$ & $7.5 \pm 1.7$ & $7.7 \pm 2.1$ & $7.6 \pm 1.9$ & 0.53 & 0.74 \\
\hline FDG-PET (hypermetabolic/not hypermetabolic) (n) & $9 / 24$ & $345 / 331$ & $101 / 103$ & & \\
\hline Tumor diameter $($ Mean $\pm \mathrm{SD}, \mathrm{cm})$ & $3.2 \pm 0.9$ & $3.3 \pm 0.9$ & $3.1 \pm 0.8$ & 0.47 & 0.45 \\
\hline Tumor volume $($ Mean $\pm \mathrm{SD}, \mathrm{ml}$ & $12.6 \pm 11.2$ & $14.3 \pm 11.6$ & $12.2 \pm 10.7$ & 0.34 & 0.82 \\
\hline ADV score $($ Mean \pm SD, $\log )$ & $3.9 \pm 1.1$ & $4.5 \pm 1.5$ & $3.9 \pm 1.2$ & 0.008 & 0.96 \\
\hline Extent of liver resection (n) & & & & $0.75^{* *}$ & $1.00 * *$ \\
\hline Trisectionectomy & 0 & 3 & 1 & & \\
\hline Hemihepatectomy & 11 & 161 & 47 & & \\
\hline Bisectionectomy & 0 & 24 & 7 & & \\
\hline Sectionectomy & 29 & 623 & 149 & & \\
\hline Segmentectomy & 5 & 29 & 21 & & \\
\hline \multicolumn{6}{|l|}{ Microvascular invasion } \\
\hline (present/absent) $(\mathrm{n})$ & $7 / 38$ & $155 / 685$ & $42 / 189$ & 0.62 & 0.67 \\
\hline Most Edmondson-Steiner grade (n) & & & & $0.59 * * *$ & $0.41 * * *$ \\
\hline Well differentiated & 12 & 255 & 74 & & \\
\hline Moderately differentiated & 23 & 443 & 104 & & \\
\hline Poorly differentiated & 10 & 140 & 47 & & \\
\hline
\end{tabular}

HBV: Hepatitis B virus; HCV: hepatitis C virus; ALD; alcoholic liver disease; AST: aspartate aminotransferase; ALT: alanine aminotransferase; AFP: $\alpha$-fetoprotein; DCP: des- $\gamma$-carboxy prothrombin; ICG-R15: indocyanine green retention test at 15 minutes; MELD: model for end-stage liver disease; FDG-PET: $2-{ }^{18}$ F-fluoro-2-deoxy-d-glucose positron emission tomography; ADV: AFP-DCP-tumor volume. *Comparison of HBV vs. nonHBV. **Hemihepatectomy or greater $v s$. sectionectomy or smaller. $* * *$ WelI-differentiated $v s$. moderately-to-poorly differentiated.

reported reduced risks with metformin treatment (22-34). Metformin has also been demonstrated to inhibit cancer cell growth and proliferation through cell cycle arrest (35). Metformin-associated antitumor effects were clearly demonstrated in our present analyses, although we did not investigate the potential action mechanisms underlying these effects. Metformin can attenuate the risk of developing HCC associated with DM in terms of dosage and medication duration, inhibiting the proliferation of hepatoma cell lines in a dose-dependent manner; further, the risk of developing HCC can also be decreased by increasing the duration of metformin use (13). Our in vitro cell line study findings also indicated that the antitumor effects of metformin appear to be dose-dependent, supporting the suggestion of high-dose long-term administration. However, these antitumor effects have been demonstrated in only high-volume cohort studies or laboratory 
Table II. Univariate analyses of factors associated with tumor recurrence and patient survival in 270 patients of the metformin and propensityscore-matching control groups.

\begin{tabular}{|c|c|c|c|c|c|}
\hline Variables & $\begin{array}{l}\text { Patient } \\
\text { No. }\end{array}$ & $\begin{array}{l}\text { Median DFS } \\
\text { period (mos) }\end{array}$ & $p$-Value & $\begin{array}{c}75 \% \text { OS } \\
\text { period (mos) }\end{array}$ & $p$-Value \\
\hline Background liver disease & & & 0.42 & & 0.88 \\
\hline HBV & 214 & 59 & & 54 & \\
\hline Non-HBV & 56 & 45 & & 51 & \\
\hline Serum AFP & & & 0.13 & & 0.46 \\
\hline$\leq 7.5 \mathrm{ng} / \mathrm{ml}$ & 137 & 59 & & 69 & \\
\hline$>7.5 \mathrm{ng} / \mathrm{ml}$ & 133 & 42 & & 50 & \\
\hline Serum DCP & & & 0.78 & & 0.32 \\
\hline$\leq 40 \mathrm{mAU} / \mathrm{m}$ & 136 & 45 & & 59 & \\
\hline$>40 \mathrm{mAU} / \mathrm{m}$ & 134 & 60 & & 47 & \\
\hline $\mathrm{ICG} \mathrm{R}_{15}(\%)$ & & & 0.071 & & 0.12 \\
\hline$\leq 10 \%$ & 61 & 67 & & 87 & \\
\hline$>10 \%$ & 140 & 42 & & 49 & \\
\hline FDG-PET & & & 0.44 & & 0.079 \\
\hline Not hypermetabolic & 127 & 67 & & 64 & \\
\hline Hypermetabolic & 110 & 49 & & 48 & \\
\hline Tumor size & & & 0.001 & & 0.006 \\
\hline$\leq 3.1 \mathrm{~cm}$ & 154 & 69 & & 91 & \\
\hline$>3.1 \mathrm{~cm}$ & 116 & 35 & & 44 & \\
\hline ADV score & & & 0.28 & & 0.97 \\
\hline$\leq 4 \log$ & 155 & 60 & & 54 & \\
\hline$>4 \log$ & 114 & 42 & & 50 & \\
\hline Microvascular invasion & & & 0.044 & & 0.25 \\
\hline Absent & & 60 & & 55 & \\
\hline Present & & 22 & & 42 & \\
\hline Tumor differentiation & & & 0.64 & & 0.16 \\
\hline WelI differentiated & 86 & 69 & & 58 & \\
\hline Moderately-to-poorly differentiated & 184 & 47 & & 49 & \\
\hline Metformin administration & & & 0.083 & & 0.032 \\
\hline No & 225 & 47 & & 49 & \\
\hline Yes & 45 & 70 & & 77 & \\
\hline
\end{tabular}

Median DFS period: disease-free survival period at 50\%; 75\% OS period, overall survival period at $75 \%$.

Table III. Multivariate analyses of factors independently associated with tumor recurrence and patient survival in 270 patients of the metformin and propensity-score-matching control groups.

\begin{tabular}{|c|c|c|c|c|c|c|}
\hline \multirow[t]{2}{*}{ Variables } & \multicolumn{3}{|c|}{ Tumor recurrence } & \multicolumn{3}{|c|}{ Patient survival } \\
\hline & Hazard ratio & $95 \% \mathrm{CI}$ & $p$-Value & Hazard ratio & $95 \% \mathrm{CI}$ & $p$-Value \\
\hline Tumor size $(>3.1 \mathrm{~cm} v s . \leq 3.1 \mathrm{~cm})$ & 1.78 & $1.23-2.59$ & 0.002 & 2.07 & $1.12-3.57$ & 0.009 \\
\hline Microvascular invasion (Present $v s$. absent) & 1.52 & $0.95-2.46$ & 0.083 & ND & & \\
\hline Metformin administration (Yes vs. no) & ND & & & 1.51 & $1.02-2.22$ & 0.042 \\
\hline
\end{tabular}

CI: Confidence interval; ND: not done.

research, implying that these effects exist but their prognostic power is not great enough to be an independent prognostic factor in small- or medium-sized volume studies. In our in vitro study, we compared the potency of antitumor effects between metformin and sorafenib, and found that the metformin- associated effects were variably comparable to those of sorafenib. This implies that some certain patients may benefit more from chemoprevention with metformin. Further laboratory studies should be performed to demonstrate its cytotoxic effects and the mechanisms underlying its antitumor effects. 

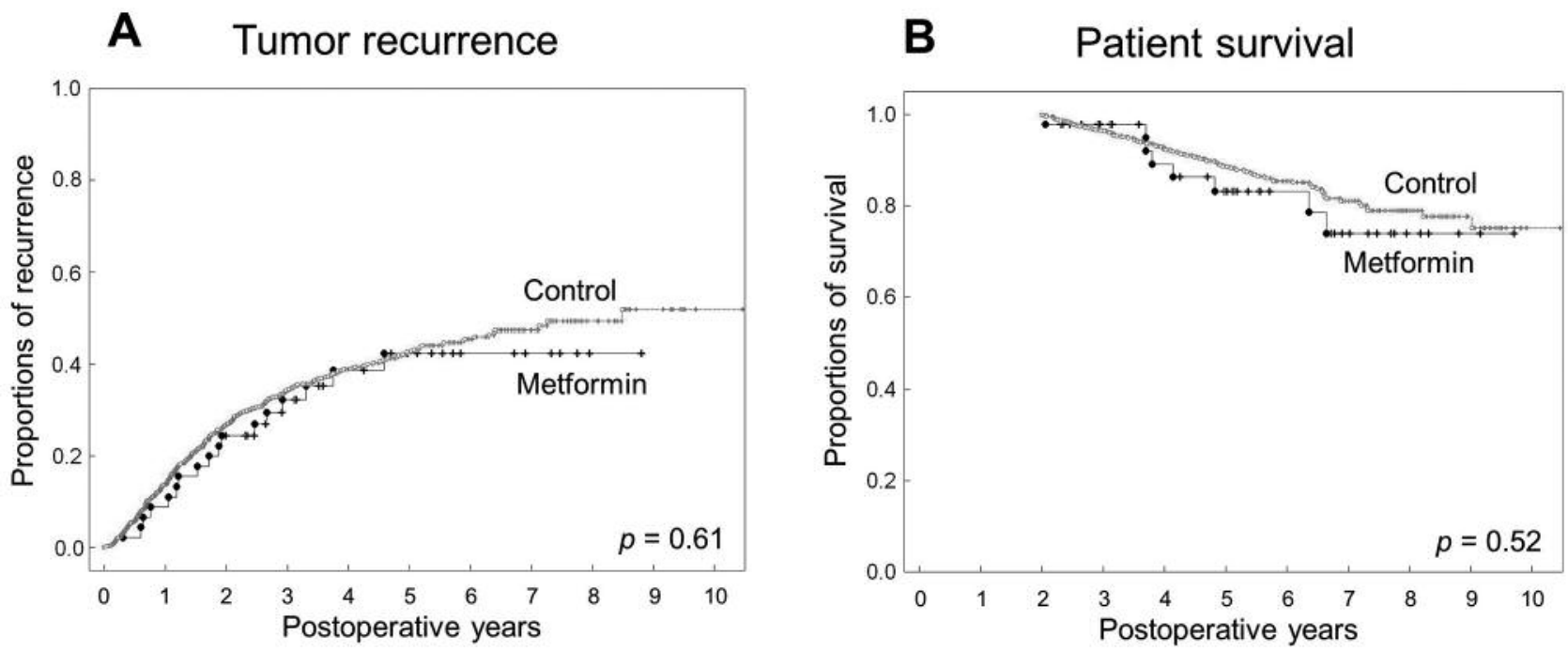

Figure 4. Comparison of tumor-recurrence (A) and overall patient survival (B) curves in the metformin study group compared to the all control group.
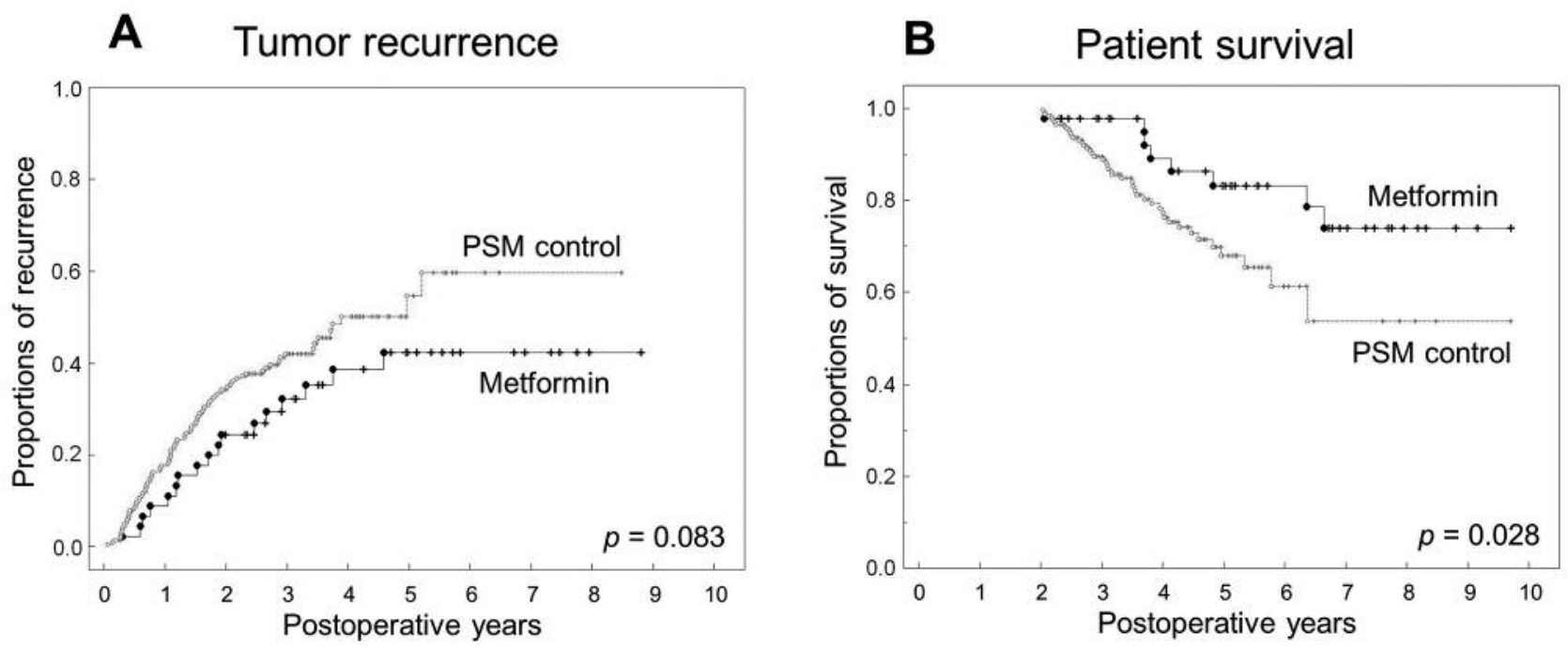

Figure 5. Comparison of tumor-recurrence (A) and overall patient survival (B) curves in the metformin study group compared to the propensity score-matching (PSM) control group.

In our clinical study with the PSM control group, the independent risk factors were a tumor size $>3.1 \mathrm{~cm}$ for tumor recurrence and a tumor size $>3.1 \mathrm{~cm}$ and metformin administration for patient survival. These results imply that metformin may be an agent for post-resection chemoprevention. Thus, further clinical studies should also be performed to establish the guidelines for patient selection and dosage setting with the aim of achieving a wide use of metformin for chemopreventive purposes.

Recently, the antitumor effect of metformin has been testified for various malignancies other than HCC. A study on metastatic castration-resistant prostate cancer revealed that metformin-docetaxel treatment significantly reduced PC 3 cell viability but it did not significantly affect cell migration or intracellular ATP levels. It was suggested that metformin may be an effective chemosensitizer for certain types of castrationresistant prostate cancer cells (36). Another study on cholangiocarcinoma presented that metformin significantly suppressed proliferation of cholangiocarcinoma cells in a dose- and time-dependent manner, that was induced by targeting signal transducer and activator of transcription 3 (STAT3) and nuclear factor-kappa B (NF-kB) (37). Another 
study also revealed that metformin induced a cell cycle arrest of gastric cancer stem cells and patient-derived primary tumor xenografts tumor study showed growth delay and decrease of the self-renewal ability of the gastric cancer stem cells (38). These studies suggest that the use of metformin can be associated with therapeutic strategy to treat various malignancies.

There were some limitations of this study of note. This was a retrospective single-center study, and the study population was not large; thus, our results may not be generalizable. It will also be necessary to validate the effects of metformin in other geographic regions to extend our results to HCC patients with various background liver diseases other than HBV infection.

In conclusion, our present in vitro laboratory study has demonstrated the existence of cytotoxic effects of metformin. Metformin administration showed a tendency to reduce the tumor recurrence rate and helped induce significant improvement in overall survival in patients who underwent HR for HCC. High-volume multicenter studies and refined laboratory studies are necessary to validate these effects on HCC.

\section{Conflicts of Interest}

No Author has any conflict of interest.

\section{Acknowledgements}

This study was supported by the Basic Science Research Program through the National Research Foundation of Korea (NRF) funded by the Ministry of Science, ICT and Future Planning (Grant No 2015R1A2A2A04007141 to Shin Hwang and 2015K1A4A3046807 to Gi-Won Song).

\section{References}

1 Forner A, Llovet JM and Bruix J: Hepatocellular carcinoma. Lancet 379: 1245-1255, 2012.

2 Cho HD, Hwang S, Lee YJ, Park KM, Kim KH, Kim JC, Ahn CS, Moon DB, Ha TY and Lee SG: Changes in the types of liver diseases requiring hepatic resection: A single-institution experience of 9016 cases over a 10 -year period. Korean J Hepatobiliary Pancreat Surg 20: 49-52, 2016.

3 El-Serag HB: Hepatocellular carcinoma. N Engl J Med 365: 1118-1127, 2011.

4 Hwang S, Lee YJ, Kim KH, Ahn CS, Moon DB, Ha TY, Song GW, Jung DH and Lee SG: The impact of tumor size on longterm survival outcomes after resection of solitary hepatocellular carcinoma: Single-institution experience with 2558 patients. J Gastrointest Surg 19: 1281-1290, 2015.

5 Chen LT, Chen MF, Li LA, Lee PH, Jeng LB, Lin DY, Wu CC, Mok KT, Chen CL, Lee WC, Chau GY, Chen YS, Lui WY, Hsiao CF, Whang-Peng $\mathbf{J}$ and Chen PJ: Long-term results of a randomized, observation-controlled, phase III trial of adjuvant interferon Alfa-2b in hepatocellular carcinoma after curative resection. Ann Surg 255: 8-17, 2012.
6 Muto Y, Moriwaki H, Ninomiya M, Adachi S, Saito A, Takasaki KT, Tanaka T, Tsurumi K, Okuno M, Tomita E, Nakamura T and Kojima T: Prevention of second primary tumors by an acyclic retinoid, polyprenoic acid, in patients with hepatocellular carcinoma. Hepatoma Prevention Study Group. N Engl J Med 334: 1561-1567, 1996.

7 Takayama T, Sekine T, Makuuchi M, Yamasaki S, Kosuge T, Yamamoto J, Shimada K, Sakamoto M, Hirohashi S, Ohashi Y and Kakizoe T: Adoptive immunotherapy to lower postsurgical recurrence rates of hepatocellular carcinoma: A randomised trial. Lancet 356: 802-807, 2000.

8 Jung DH, Hwang S, Song GW, Ryoo BY, Kim N, Tak E and Hong HN: An interim safety analysis of hepatocellular carcinoma patients administrating oral vitamin $\mathrm{K}$ with or without sorafenib. Korean J Hepatobiliary Pancreat Surg 19: 1-5, 2015.

9 Ben Sahra I, Regazzetti C, Robert G, Laurent K, Le MarchandBrustel Y, Auberger P, Tanti JF, Giorgetti-Peraldi S and Bost F: Metformin, independent of AMPK, induces mTOR inhibition and cell-cycle arrest through REDD1. Cancer Res 71: 43664372, 2011

10 Buzzai M, Jones RG, Amaravadi RK, Lum JJ, DeBerardinis RJ, Zhao F, Viollet B and Thompson CB: Systemic treatment with the antidiabetic drug metformin selectively impairs p53-deficient tumor cell growth. Cancer Res 67: 6745-6752, 2007.

11 Dowling RJ, Zakikhani M, Fantus IG, Pollak M and Sonenberg $\mathrm{N}$ : Metformin inhibits mammalian target of rapamycindependent translation initiation in breast cancer cells. Cancer Res 67: 10804-10812, 2007.

12 Zakikhani M, Dowling R, Fantus IG, Sonenberg N and Pollak M: Metformin is an AMP kinase-dependent growth inhibitor for breast cancer cells. Cancer Res 66: 10269-10273, 2006.

13 Chen HP, Shieh JJ, Chang CC, Chen TT, Lin JT, Wu MS, Lin $\mathrm{JH}$ and $\mathrm{Wu} \mathrm{CY}$ : Metformin decreases hepatocellular carcinoma risk in a dose-dependent manner: Population-based and in vitro studies. Gut 62: 606-615, 2013.

14 Donadon V, Balbi M, Mas MD, Casarin P and Zanette G: Metformin and reduced risk of hepatocellular carcinoma in diabetic patients with chronic liver disease. Liver Int 30: 750758, 2010.

15 Lai SW, Chen PC, Liao KF, Muo CH, Lin CC and Sung FC: Risk of hepatocellular carcinoma in diabetic patients and risk reduction associated with anti-diabetic therapy: a populationbased cohort study. Am J Gastroenterol 107: 46-52, 2012.

16 Kajbaf F, De Broe ME and Lalau JD: Therapeutic concentrations of metformin: A systematic review. Clin Pharmacokinet 55: 439459, 2016.

17 Ha TY, Hwang S, Moon KM, Won YJ, Song GW, Kim N, Tak E, Ryoo BY and Hong HN: Sorafenib inhibits migration and invasion of hepatocellular carcinoma cells through suppression of matrix metalloproteinase expression. Anticancer Res 35: 1967-1976, 2015.

18 Guo S and Fraser MW: Propensity score analysis: Statistical methods and applications. Advanced Quantitative Techniques in the Social Sciences Series. Los Angeles: SAGE Publications, Inc; 2010.

19 Hwang S, Song GW, Lee YJ, Kim KH, Ahn CS, Moon DB, Ha TY, Jung DH, Park GC and Lee SG: Multiplication of tumor volume by two tumor markers is a post-resection prognostic predictor for solitary hepatocellular carcinoma. J Gastrointest Surg 20: 1807-1820, 2016. 
20 Jung DH, Hwang S, Lee YJ, Kim KH, Song GW, Ahn CS, Moon DB and Lee SGl: Small hepatocellular carcinoma with low tumor marker expression benefits more from anatomical resection than tumors with aggressive biology. Ann Surg, 2017. doi: 10.1097/SLA.0000000000002486. [Epub ahead of print].

21 The Korean Association for the Study of the Liver (KASL): KASL clinical practice guidelines: management of chronic hepatitis B. Clin Mol Hepatol 22: 18-75, 2016.

22 Yoshida H, Shiratori Y, Kudo M, Shiina S, Mizuta T, Kojiro M, Yamamoto K, Koike Y, Saito K, Koyanagi N, Kawabe T, Kawazoe S, Kobashi H, Kasugai H, Osaki Y, Araki Y, Izumi N, Oka H, Tsuji K, Toyota J, Seki T, Osawa T, Masaki N, Ichinose M, Seike M, Ishikawa A, Ueno Y, Tagawa K, Kuromatsu R, Sakisaka S, Ikeda H, Kuroda H, Kokuryu H, Yamashita T, Sakaida I, Katamoto T, Kikuchi K, Nomoto M and Omata M: Effect of vitamin $\mathrm{K} 2$ on the recurrence of hepatocellular carcinoma. Hepatology 54: 532-540, 2011.

23 Zhong JH, Mo XS, Xiang BD, Yuan WP, Jiang JF, Xie GS and Li LQ: Postoperative use of the chemopreventive vitamin K2 analog in patients with hepatocellular carcinoma. PLoS One 8: e58082, 2013.

24 Ha TY, Hwang S, Hong HN, Choi YI, Yoon SY, Won YJ, Song GW, Kim N, Tak E and Ryoo BY: Synergistic effect of sorafenib and vitamin $\mathrm{K}$ on suppression of hepatocellular carcinoma cell migration and metastasis. Anticancer Res 35: 1985-1995, 2015.

25 Jung DH, Hwang S, Song GW, Ryoo BY, Kim N, Tak E and Hong HN: An interim safety analysis of hepatocellular carcinoma patients administrating oral vitamin $\mathrm{K}$ with or without sorafenib. Korean J Hepatobiliary Pancreat Surg 19: 1-5, 2015.

26 Davila JA, Morgan RO, Shaib Y, McGlynn KA and El-Serag HB: Diabetes increases the risk of hepatocellular carcinoma in the United States: A population-based case control study. Gut 54: 533-539, 2005.

27 El-Serag HB, Hampel $\mathrm{H}$ and Javadi F: The association between diabetes and hepatocellular carcinoma: A systematic review of epidemiologic evidence. Clin Gastroenterol Hepatol 4: 369-380, 2006.

28 Veldt BJ, Chen W, Heathcote EJ, Wedemeyer H, Reichen J, Hofmann WP, de Knegt RJ, Zeuzem S, Manns MP, Hansen BE, Schalm SW and Janssen HL: Increased risk of hepatocellular carcinoma among patients with hepatitis $\mathrm{C}$ cirrhosis and diabetes mellitus. Hepatology 47: 1856-1862, 2008.

29 Noto H, Osame K, Sasazuki T and Noda M: Substantially increased risk of cancer in patients with diabetes mellitus: A systematic review and meta-analysis of epidemiologic evidence in Japan. J Diabetes Complications 24: 345-353, 2010.
30 Giovannucci E, Harlan DM, Archer MC, Bergenstal RM, Gapstur SM, Habel LA, Pollak M, Regensteiner JG and Yee D: Diabetes and cancer: a consensus report Diabetes Care 33: 16741685, 2010.

31 Lam EK, Batty GD, Huxley RR, Martiniuk AL, Barzi F, Lam TH, Lawes CM, Giles GG, Welborn T, Ueshima H, Tamakoshi A, Woo J, Kim HC, Fang X, Czernichow S, Woodward M and Asia Pacific Cohort Studies Collaboration: Associations of diabetes mellitus with site-specific cancer mortality in the AsiaPacific region. Ann Oncol 22: 730-738, 2011.

32 Chan KM, Kuo CF, Hsu JT, Chiou MJ, Wang YC, Wu TH, Lee $\mathrm{CF}, \mathrm{Wu} \mathrm{TJ}$, Chou HS and Lee WC: Metformin confers risk reduction for developing hepatocellular carcinoma recurrence after liver resection. Liver Int 37: 434-441, 2017.

33 Hassan MM, Curley SA, Li D, Kaseb A, Davila M, Abdalla EK, Javle M, Moghazy DM, Lozano RD, Abbruzzese JL and Vauthey $\mathrm{JN}$ : Association of diabetes duration and diabetes treatment with the risk of hepatocellular carcinoma. Cancer 116: 1938-1946, 2010.

34 Lee MS, Hsu CC, Wahlqvist ML, Tsai HN, Chang YH and Huang YC: Type 2 diabetes increases and metformin reduces total, colorectal, liver and pancreatic cancer incidences in Taiwanese: A representative population prospective cohort study of 800,000 individuals. BMC Cancer 11: 20, 2011.

35 Ben Sahra I, Laurent K, Loubat A, Giorgetti-Peraldi S, Colosetti P, Auberger P, JF, Le Marchand-Brustel Y and Bost F: The antidiabetic drug metformin exerts an antitumoral effect in vitro and in vivo through a decrease of cyclin D1 level. Oncogene 27: 3576-3586, 2008.

36 Mayer MJ, Klotz LH and Venkateswaran V: Evaluating metformin as a potential chemosensitizing agent when combined with docetaxel chemotherapy in castration-resistant prostate cancer cells. Anticancer Res 37: 6601-6607, 2017.

37 Saengboonmee C, Seubwai W, Cha'on U, Sawanyawisuth K, Wongkham S and Wongkham C: Metformin exerts antiproliferative and anti-metastatic effects against cholangiocarcinoma cells by targeting STAT3 and NF-kB. Anticancer Res 37: 115-123, 2017.

38 Courtois S, Durán RV, Giraud J, Sifré E, Izotte J, Mégraud F, Lehours $\mathrm{P}$, Varon $\mathrm{C}$ and Bessède $\mathrm{E}$ : Metformin targets gastric cancer stem cells. Eur J Cancer 84: 193-201, 2017.

Received December 19, 2017

Revised February 4, 2018

Accepted February 5, 2018 